\title{
STENOSIS OF THE LEFT ATRIO-VENTRICULAR CANAL
}

\author{
BY
}

\author{
T. B. STRETTON AND P. H. FENTEM
}

From the Departments of Cardiology and Pathology, Manchester Royal Infirmary

Congenital mitral stenosis is rare and may occur in association with other congenital abnormalities of the heart and great vessels (Ferencz et al., 1954). A similar functional effect may be produced by two even rarer malformations. These are cor triatriatum (Pedersen and Therkelsen, 1954) and supravalvular stenosing ring of the left atrium (Rogers et al., 1955). In cor triatriatum the left atrium is divided into two chambers by a diaphragm perforated by one or more openings. The pulmonary veins enter the upper chamber; the cavity of the atrial appendage is part of the lower chamber. The diaphragm may obstruct the left atrium and this can be corrected surgically (Belcher and Somerville, 1959). Rogers and his co-workers (1955) described a shelf-like ring situated above the orifice of the mitral valve: they believed that this "supravalvular stenosing ring" was an acquired lesion, due to underlying mitral regurgitation. Manubens et al. (1960) have shown, however, that this is not necessarily so and that the abnormality may be successfully repaired at operation.

\section{Case Report}

A youth of 17 years was admitted to hospital in December 1959 . He was known to have had a cardiac lesion since birth. He had always been breathless on exertion and had avoided games at school. Four years previously he had been in hospital with heart failure, probably precipitated by the onset of atrial fibrillation. For many years he had had attacks of bronchial asthma.

On examination he had a pronounced dorsal kyphosis and was barrel-chested. There was controlled atrial fibrillation; the blood pressure was 140/80. The apex beat was in the fifth intercostal space $2.5 \mathrm{~cm}$. beyond the mid-clavicular line, and was left ventricular in character. The first heart sound was normal; the second sound in the pulmonary area was loud. There was no opening snap. A loud systolic murmur was heard over the entire præcordium. It was of equal intensity at the apex and in the aortic area; it was also audible over the carotid vessels. There was a long, apical mid-diastolic murmur. The venous pressure was normal and there was no œdema. His chest expansion was poor; high-pitched rhonchi were heard over both lungs.

The electrocardiogram showed atrial fibrillation. There was right axis deviation and the $\mathbf{R}$ and $\mathbf{S}$ waves were of equal amplitude across the entire præcordium; prominent $Q$ waves were seen from V4 to V6; S-T depression was present in leads V1 to V4. These changes were considered to be consistent with biventricular enlargement.

Chest X-rays showed a severe dorsal kyphosis and enlargement of the left atrium and both ventricles; the pulmonary vascularity was increased.

Cardiac catheterization was performed. The mean pulmonary capillary venous (P.C.V.) pressure was raised to $17 \mathrm{~mm}$. Hg. The pulmonary arterial pressure was $88 / 47 \mathrm{~mm}$. $\mathrm{Hg}$ (mean pressure $61 \mathrm{~mm}$. $\mathrm{Hg}$ ). The right ventricular pressure was $83 / 0 \mathrm{~mm}$. $\mathrm{Hg}$ and the mean right atrial pressure was $-2 \mathrm{~mm}$. $\mathrm{Hg}$. The pulmonary arterial blood was 60 per cent saturated with oxygen; right ventricular blood was 45 per cent saturated. Simultaneous brachial and femoral arterial samples were 89 per cent and 80 per cent respectively; after the patient had breathed oxygen for fifteen minutes these rose to 94 per cent and 92 per cent. A patent ductus arteriosus was demonstrated, and a left-sided superior vena cava also. The findings were those 
of pulmonary hypertension with a bidirectional shunt at aorto-pulmonary level; the shunt was predominantly left to right. Mitral stenosis was presumed to be present because of the raised P.C.V. pressure in the absence of left ventricular failure. Operation was advised to relieve the presumed mitral stenosis and to ligate the ductus arteriosus after a preliminary trial of the effect of clamping this.

At operation, on October 31, 1960, Mr. A. G. Riddell explored the left atrium through the appendage. He discovered a thin, transverse, diaphragmatic structure containing a central hole about $0.5 \mathrm{~cm}$. in diameter. $\mathrm{He}$ also noted that the valve itself, just beneath this diaphragm, appeared to function normally; there was no regurgitant jet. The hole in the diaphragm was dilated with a finger. As the atrial incision was being closed ventricular fibrillation occurred and this proved irreversible; attempts at defibrillation were unsuccessful and cardiac massage was discontinued after an hour.

At necropsy the heart was found to be greatly enlarged; it weighed $450 \mathrm{~g}$. The pericardial sac contained about $20 \mathrm{ml}$. of blood. The heart was globular, with a large right ventricle and a small, rounded, left ventricle rotated posteriorly. The right atrium was of normal size; the coronary sinus was large, its opening into the 
right atrium being $2.7 \mathrm{~cm}$. in diameter. A left superior vena cava, larger than the right, drained into the coronary sinus. The foramen ovale was closed. The right ventricle was dilated and grossly hypertrophied, the wall being 1.0 to $1.7 \mathrm{~cm}$. thick. The tricuspid and pulmonary valves appeared normal. The ductus arteriosus was so short that the main pulmonary artery appeared to communicate directly at its bifurcation with the arch of the aorta. The communication was $1.2 \mathrm{~cm}$. in diameter. The pulmonary artery and its two main branches were dilated. The left atrium was dilated. Four normal pulmonary veins drained into it. The left auricular appendage had been opened surgically.

There was an unusual anomaly in the region of the mitral valve. Viewed from above, the orifice was reduced to a hole $1.4 \mathrm{~cm}$. in diameter by a crescentic diaphragm (Fig. 1). (Before dilatation at operation this orifice had been noted to be $0.5 \mathrm{~cm}$. in diameter). The diaphragm was incomplete anteriorly, where a fibrous band $1 \mathrm{~mm}$. thick crossed the opening. The posterior mitral cusp was flimsy and poorly developed and was attached about $2 \mathrm{~mm}$. from the free edge of this diaphragm. The attachment of the valve cusp to this diaphragm is illustrated in Fig. 2. The anterior cusp was slightly thickened. The chordæ tendineæ appeared normal. The left ventricle was hypertrophied; its cavity was small. The aortic valve was bicuspid. Above the anterior cusp there was a single coronary ostium; the two main coronary arteries arose $3 \mathrm{~mm}$. from this opening. Below the anterior cusp was a transverse ledge of fibrous tissue $2 \mathrm{~mm}$. wide and $3 \mathrm{~cm}$. long, attached to the ventricular wall. No diffuse endocardial thickening was observed in any of the cardiac chambers. The coronary arteries were patent and healthy throughout their length.

The arch of the aorta and descending aorta were hypoplastic, the lumen being $1.4 \mathrm{~cm}$. in diameter. Immediately distal to the patent ductus arteriosus the aorta was narrowed to $1.0 \mathrm{~cm}$. over a segment $4 \mathrm{~mm}$. long. This was due to a ring of collagen situated in the adventitia.

Microscopic examination of the stenosing ring showed that the shelf consisted of fibrous tissue which originated in the substance of the endocardium. At the point of attachment of the posterior valve cusp the fibres divided into two bundles, some fibres passing towards the free edge of the shelf (Fig. 2), where they were intimately mixed with collagenous fibres of the shelf; the other bundle passed into the valve cusp. The ventricular collagenous layer of the posterior cusp was thickened by degenerate collagen and the arrangement of collagen fibres was not as

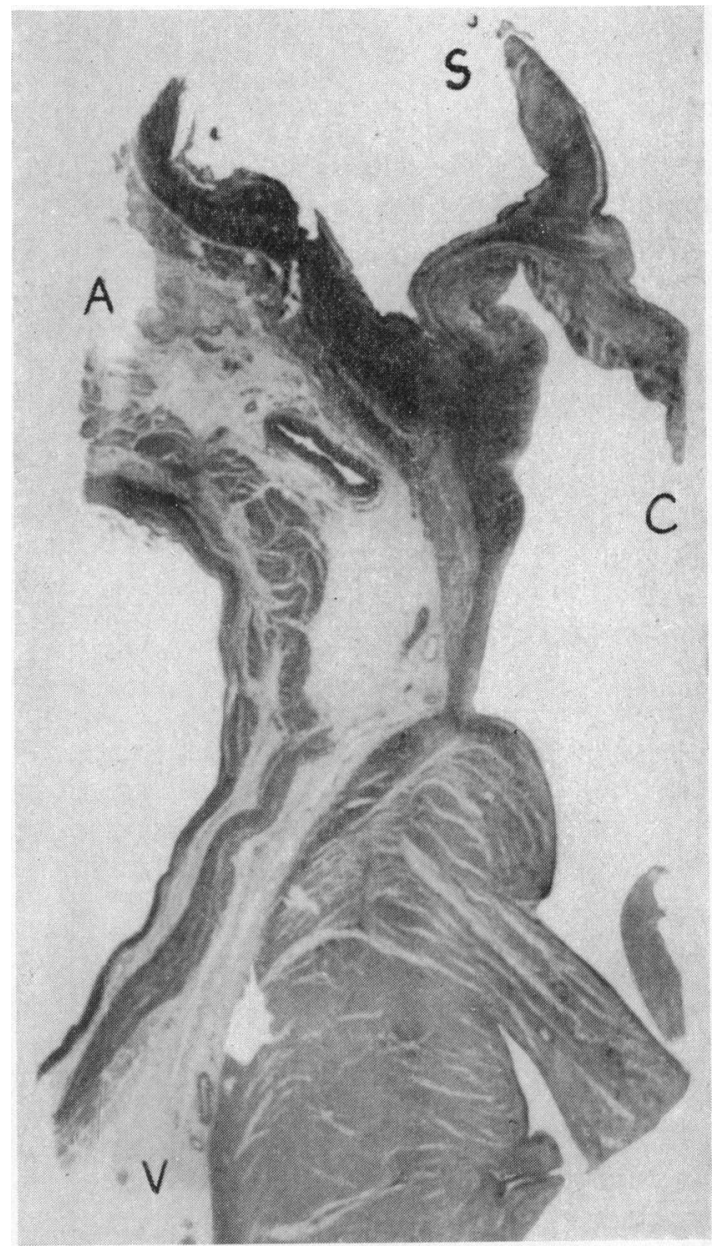

FIG. 2.-A low-power view of a section through the mitral annulus and the atrial and ventricular septa to show the attachment of the posterior mitral cusp (C) to the shelf-like ring (S). The major portion of the section consists of the atrial septum (A) in the upper part and the ventricular septum (V) in the lower. Attached to the lower atrial septum is a shelf-like ring, the free edge of which has turned upwards during fixation. The free edge of the mitral cusp points downwards.

orderly as usual; the auricular fibro-elastic layer showed some diminution in elastic fibres. The endocardium of the left atrium was thicker than that of the right to an extent slightly greater than normal. In several areas there were localized thickenings which consisted of intermixed collagen and elastic tissue. The left ventricular endocardium at the base of the valve was thickened by degenerate collagen. The muscle fibres were patchily hypertrophied in the walls of both ventricles but otherwise the myocardium appeared healthy. 
The lungs were of normal weight. The left lung was collapsed. There were fine fibrous adhesions over the lateral surface of the right lung. The horizontal fissure of this lung was incomplete, so that separation of the middle lobe was only established in the posterior one-third of the fissure. The pulmonary vessels of all sizes were healthy and there was no macroscopic or histological evidence of pulmonary hypertension.

The notable feature in the examination of the remaining organs was the small size of the liver $(840 \mathrm{~g}$.) and the kidneys, the right weighing $65 \mathrm{~g}$. the left $70 \mathrm{~g}$.

\section{Discussion}

The patient described had multiple congenital abnormalities of the heart but the lesion of particular interest was the crescentic shelf-like structure attached to the annulus of the mitral valve. The shelf was producing a stenosis of the left atrio-ventricular canal at this level. Similar "stenosing rings" have been described previously (Manubens et al., 1960) but all have had a supravalvular attachment. In each instance there has been some other congenital anomaly of the heart or great vessels.

Rogers and his associates (1955) decided that the "stenosing ring" in the left atrium was essentially a regurgitant jet lesion produced by mitral regurgitation. Regurgitant jets of blood most commonly produce a simple plaque of fibrous tissue where the blood impinges. They may, however, form a cusp-like pocket in the endocardium (Edwards and Burchell, 1958). Rogers suggested that the regurgitant jet of blood was, in their patient, redirected by its initial jet lesion and thereby it produced a continuous succession of jet lesions just above the mitral valve. This, they concluded, was the mode of production of the shelf-like structure or stenosing ring.

It seems unlikely that this could explain the formation of a structure such as that seen in the present case. Furthermore, there was no evidence of mitral regurgitation. The findings in this case support the contention of Manubens et al. (1960) that the stenosis is a true congenital malformation, though its mode of development is obscure. As the shelf and one mitral valve cusp appear as a single structure in the heart described here it is possible that the anomaly was produced by faulty division of the valve cushions during the development of the left atrio-ventricular canal.

\section{Summary}

A patient is described who presented clinically with mitral stenosis and a patent ductus arteriosus. He was found at autopsy to have a stenosis of the left atrio-ventricular canal produced by a shelflike ring attached to the annulus of the mitral valve. The clinical and pathological features are described and reference is made to similar cases.

We thank Dr. E. G. Wade for his encouragement and permission to publish this case; our thanks are due also to Professor A. C. P. Campbell, Dr. A. Morgan Jones and Mr. A. G. Riddell; to Mr. N. Mowat for technical assistance, and to the Department of Medical Illustration at Manchester Royal Infirmary for the illustrations.

\section{References}

Belcher, J. R., and Somerville, W. (1959). Brit. med. J., 1, 1281.

Edwards, J. E., and Burchell, H. B. (1958). Circulation, 18, 949.

Ferencz, C., Johnson, A. L., and Wiglesworth, F. W. (1954). Circulation, 9, 161.

Manubens, R., Krovetz, L. J., and Adams, P., Jr. (1960). Amer. Heart J., 60, 286.

Pedersen, A., and Therkelsen, F. (1954). Amer. Heart J., 47, 676.

Rogers, H. M., Waldron, B. R., Murphey, D. F. H., and Edwards, J. E. (1955). Amer. Heart J., 50, 777. 